\title{
INTRODUCTION OF FATIGUE MARKERS IN FULL SCALE FATIGUE TEST OF AN AIRCRAFT STRUCTURE
}

\author{
Andrzej Leski ${ }^{1}$ \\ Sylwester Klysz ${ }^{1,2}$ \\ Janusz Lisiecki ${ }^{1}$ \\ Gabriel Gmurczyk ${ }^{1}$ \\ Piotr Reymer ${ }^{1}$ \\ Dariusz Bochenek $^{1}$ \\ Dariusz Zasada ${ }^{3}$
}

\begin{abstract}
Air Force Institute of Technology, Warsaw, Poland ${ }^{1}$
University of Warmia and Mazury, Olsztyn, Poland ${ }^{2}$

Military University of Technology, Warsaw, Poland ${ }^{3}$
\end{abstract}

\begin{abstract}
Air Force Institute of Technology participates in the service life assessment programme SEWST. The aim of this programme, funded by the Polish Ministry of Defense, is to modify the operation system of PZL-130 "Orlik" TC-II turbo propelled trainer aircraft. The structural part of the programme is focused on the Full Scale Fatigue Test of the whole airframe to be conducted at the VZLU in the Czech Republic. The load spectrum for the test was developed by the AFIT based on the flight test results. The basic load block represents 200 simulated flight hours and consists of 194 flights showing different levels of severity.

At the end of the Full Scale Fatigue Test a teardown inspection is planned during which it would be most beneficial to be able to determine crack propagation rate by means of a crack surface inspection. Markers are usually visible on most fatigue crack surfaces, however they occur randomly therefore it is almost impossible to conclude anything about the crack history. Since the preliminary load block consisted of separate flights (flight loads together with landing and taxing loads) showing significantly different levels of severity, the easiest way to modify the load block was to change the order of flights within the block. Hence a pilot programme was started at the AFIT which was focused on the determination of the influence of flight sequence on crack appearance. Several load blocks were determined using various techniques of rearranging the order of flights within the preliminary load spectrum.

This approach ensured the preservation of the initial severity of the load block and simultaneously enabled a significant increase in the probability of the markers occurrence introducing neither artificial underloads nor overloads that would most probably affect the crack propagation rate.

Fatigue crack surfaces were inspected using Scanning Electron Microscope. As a result of the investigations a series of images were obtained showing the specimen microstructure with visible markers arranged in the desired sequences. Based on the obtained pictures the most promising load block arrangements were chosen for the Full Scale Fatigue Test.
\end{abstract}

Keywords: Full Scale Fatigue Test, fatigue markers, load block rearrangement 


\section{INTRODUCTION}

The analysis of the marker introduction methods for Full Scale Fatigue Test shows that there are several strategies to achieve the desired effect. The selection of a method appropriate to a particular case is a difficult issue and stating definitely weather the adopted method was effective or not may be possible only during the fractographic study after completion of the test. Strategies for the variable amplitude spectra, particularly for the full scale aircraft fatigue testing mentioned in the articles [1,2], suggest that the most advantageous from the point of view of reliability of the results is the method of sorting the entire flight spectrum.

The sequence used in the study was established by repeating the loads recorded during 19 flights so as to finally achieve 197 flights in the spectrum (corresponding to 200 hours of simulated flight) [3]. In the study, a spectrum prepared for the implementation in the Full Scale Fatigue Test of PZL-130 "Orlik" TC-II was used. The prepared load sequence includes the load structure for a wide range of applications and different aspects of aircraft operation and is based on the load measurements recorded during the flight tests in which the following elements were included [4]: circle flights and touch-and-go landings, advanced flights maneuvers, flight to measure the vibrations caused by tail buffeting, flying through the clouds with a relatively low maneuverability. The intensity factor of the load spectrum, verified as a number of load cycles between individual load levels is kept at a level that corresponds to the specific flight profile for the PZL-130 "Orlik" TC-I aircraft operated by the Polish Air Force.

To verify the effectiveness of introducing markers into the planned full-scale load spectrum fatigue test of PZL-130 "Orlik" TC-II, the fatigue coupon tests were carried out with the 810.23 MTS fatigue-endurance machine, using the WOL samples. The study was conducted at the Laboratory of Strength of Materials at the AFIT (accreditation certificate AB 430). Fractographic studies were carried out at the Military University of Technology in Warsaw using the new electron microscope Quanta 3D FEG DualBeam, equipped with a Schottky field emission gun.

\section{THE CONCEPT OF INTRODUCING MARKERS INTO THE FATIGUE LOAD TESTS SPECTRUM}

Generally, the range of the load spectrum modification may be:

1. Zero; natural markers appearing in the spectrum of the output,

2. Small, introduction of a single or a few extra cycles of load in a specific sequence,

3. Large, introduction of a single or a few extra blocks of load (load strategy) in a specific sequence.

The analysis of the literature shows that there is no fixed relationship between the positive effects of such modifications, which makes clear the choice of options for a particular research purpose [1]. Furthermore, many experimental tests showed that the effects observed for the selected option of modification for one type of material were not obtained for other materials or for different cycle amplitudes, occurence frequency or load frequency. Unfortunately, it is very hard to obtain unequivocal results as such investigations require very sophisticated equipment. Typically, the assessment of the nature of the fatigue crack growth requires a high magnification microscope and experienced personnel, in particular for the purpose of the analysis and interpretation of the crack surface. In the case of Full Scale Fatigue Test of entire structures lasting several months, the speed of crack propagation is low necessitating the use of advanced scanning microscopy.

At the stage of the preparation of the load spectrum for the Full Scale Fatigue Test, a flight arrangement was determined to provide the appearance of visible markers in the structure of the crack. Flights were reorganized in such a way that flights of larger amplitude loads were 
interspersed with flights of smaller amplitude loads - which seemed to be easy to implement in practice.

It is assumed that the spectrum loads for the Full Scale Fatigue Test of the airframe structure will be prepared based on the strain waveforms recorded during the flight tests. During the measurements, the loads on the airframe structure were recorded by 116 sensors at 27 characteristic places - Figure 1 [6]. The key to prepare the load spectrum was the SLMX14 sensor recording the value of the bending moment at the base of the left wing. As a result of applying the filtering algorithms appropriate to the waveforms obtained from the measurements, the output load spectrum for Full Scale Fatigue Test was obtained (Fig. 2) - the two waveforms, corresponding to the different data filtering thresholds, gave a different number of cycles of the maximum values: the spectrum a) 17 and the spectrum b) 42 .

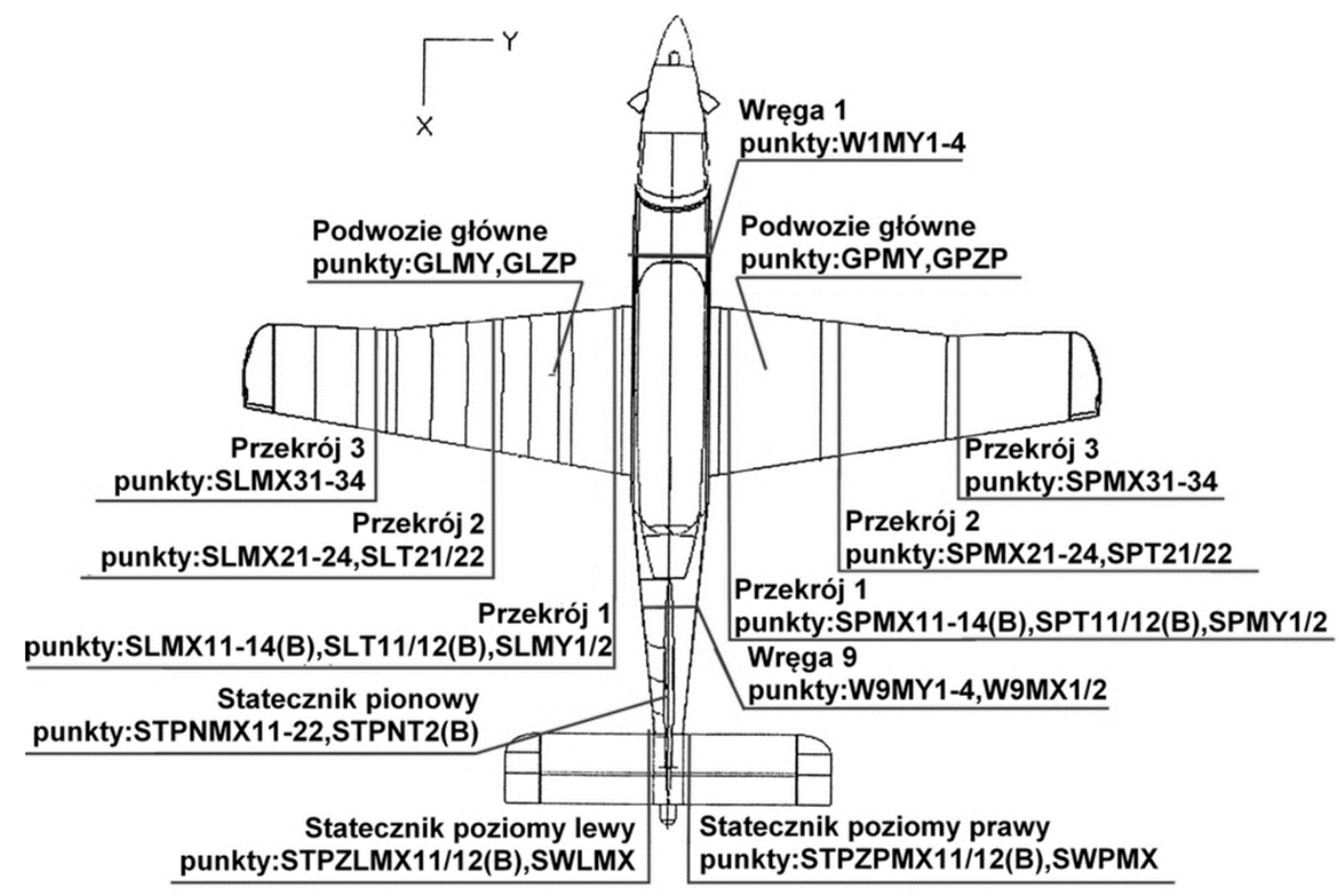

Fig. 1. Arrangement of sections and measurement points on the airframe of PZL-130 "Orlik" TC-II [6]

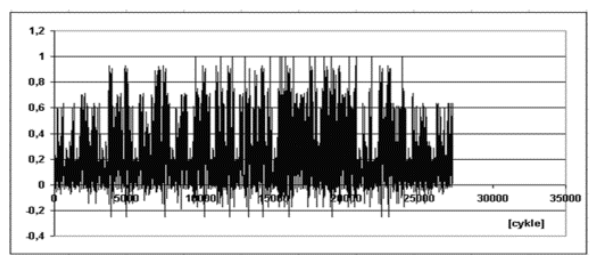

a)

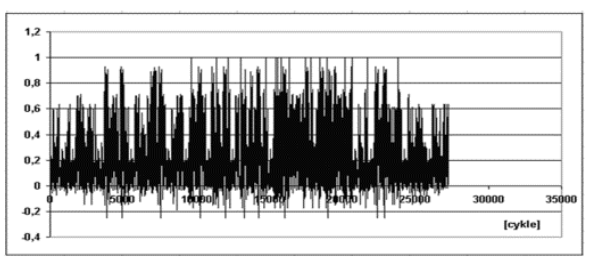

b)

Fig. 2. Output load spectrum determined from measurements a) Block no. 17, b) block no. 42 


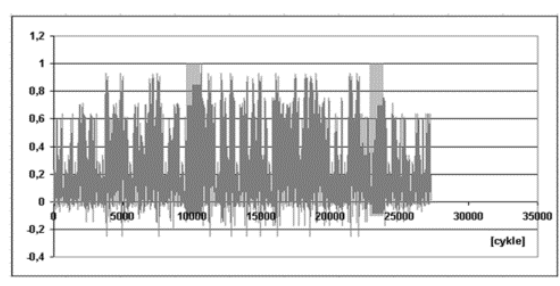

a)

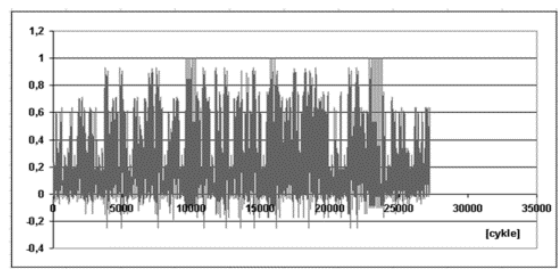

c)

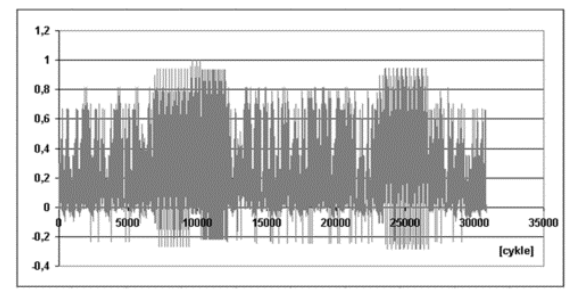

b)

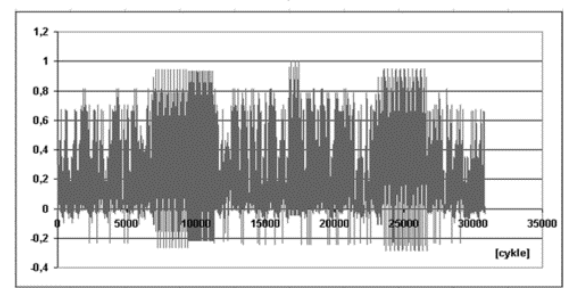

d)

Fig. 3. Modified load spectra (natural markers) for the output spectrum (Fig. 2). a) (9-8) marker, b) $(31+11)$ marker, c) $(6+3+8)$ marker, d) $(28+3+11)$ marker

Output spectra were modified - Fig. 3, in the natural markers variant, by changing the order of the load sequence (reordering) as a marker for the type (9-8) and (6-3-8) (the spectrum of Fig. 2a) and as a marker of the type (31-11) and (28-3-11) (the spectrum of Fig. 2b). Only selected flights were moved. Artificial markers in the form of a sequence of cycles of varying levels of loads were added between the blocks corresponding to the load output value of the spectrum in Figure 2. Several variants were planned - Figures 4 and 5.

- As the simulation of natural markers:
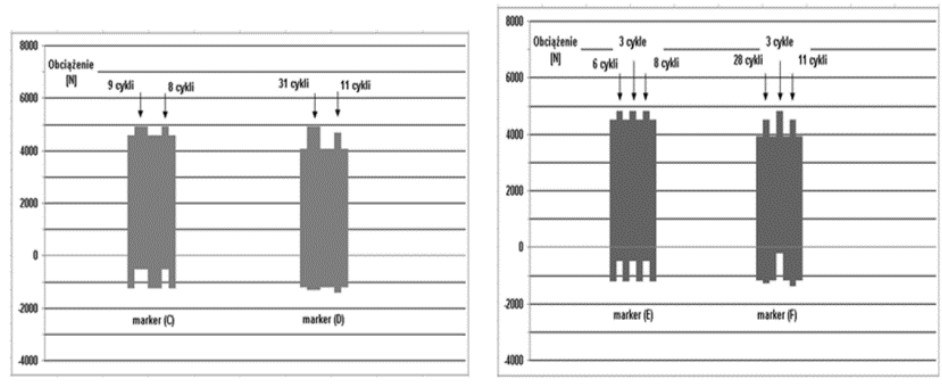

$(9+8)$ marker *, $(31+11)$ marker *; $(6+3+8)^{*}$ marker, $(28+3+11)^{*}$ marker
- As a series of different $\mathrm{R}$ asymmetry coefficient overloads

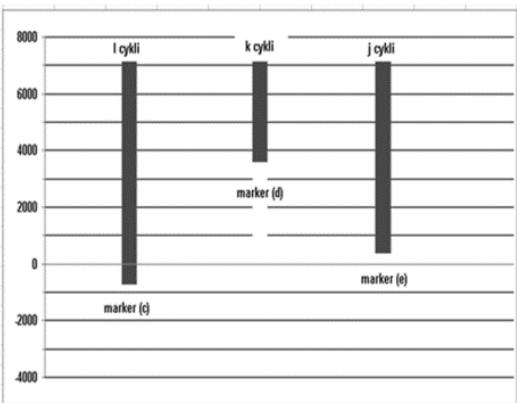

- (6-4-10) markers with different $\mathrm{R}$ asymmetry coefficients

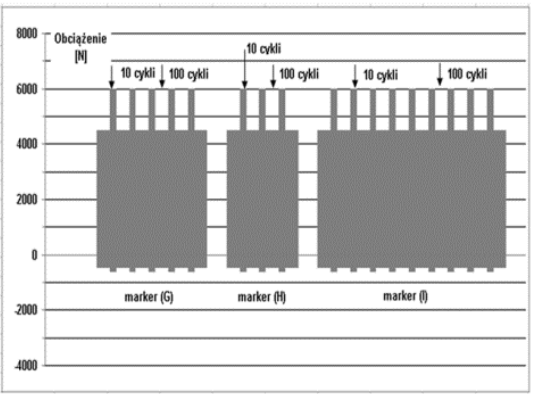

- As a single marker of different R asymmetry coefficients

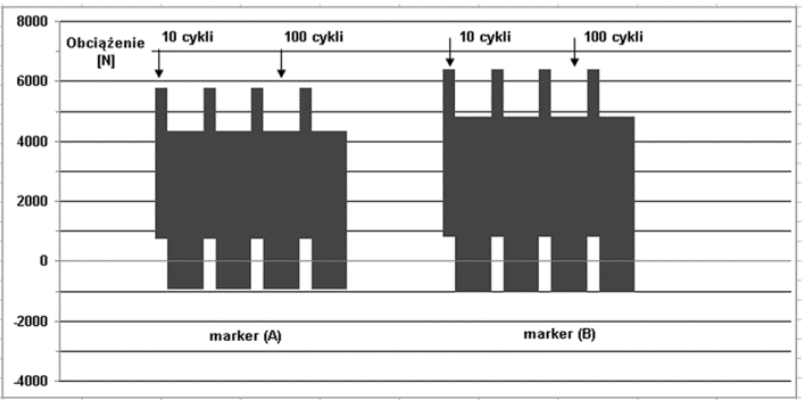

Fig. 4. Variants of artificial markers 

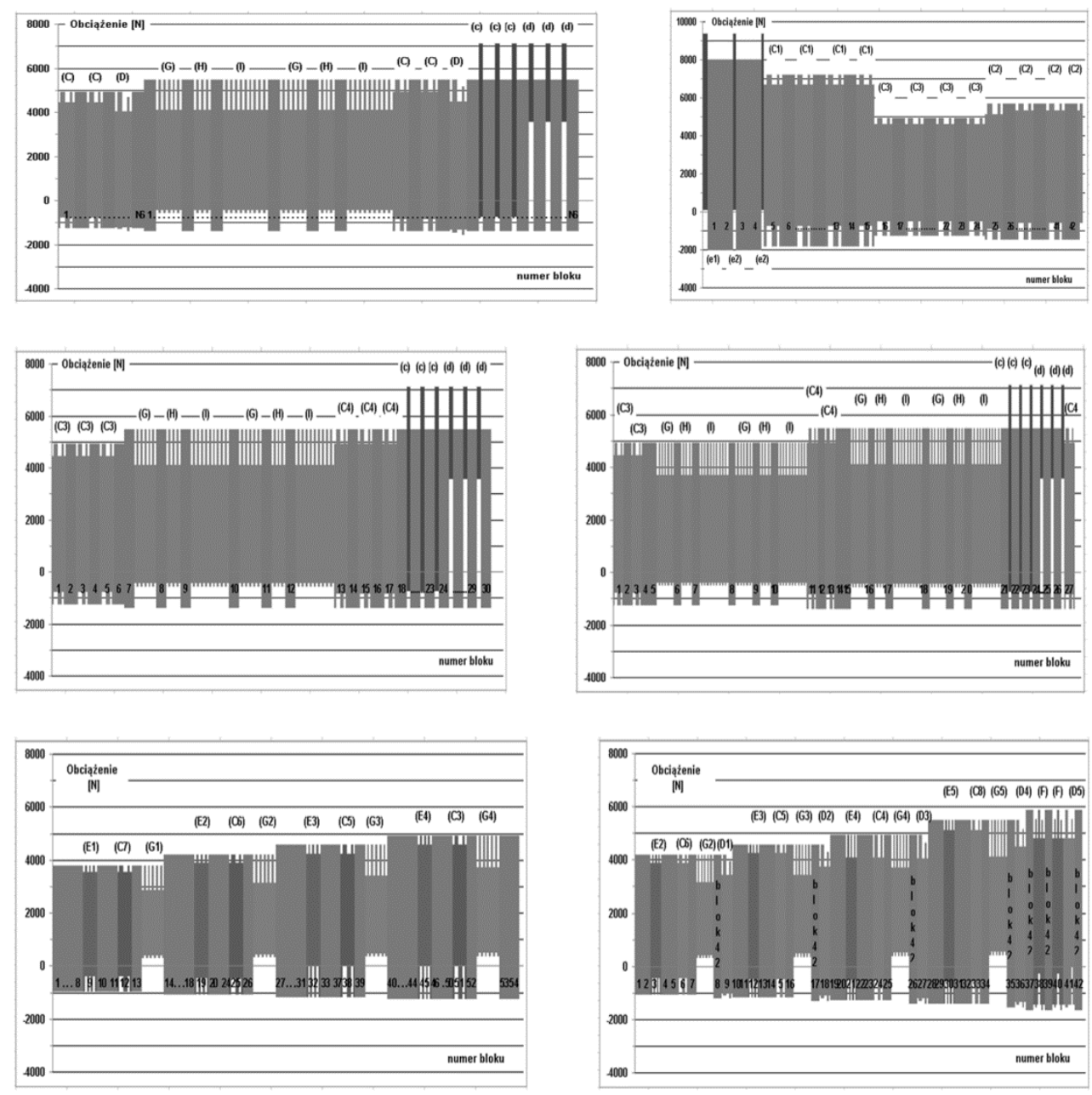

Fig. 5. Variants of load spectra for the implementation of fatigue tests

\section{IMPLEMENTATION OF FATIGUE TESTS}

On the basis of the artificial markers, a fatigue spectrum was configured. Pilot tests were carried out using samples shown in Figure 6.

The shape and dimensions of the aluminum alloy WOL samples (Wedge Opening Loaded Specimen) are shown in Figure 5.

The thickness of the samples was $\mathrm{t}=5.45 \mathrm{~mm}$, the width $\mathrm{W}=63.8 \mathrm{~mm}$.

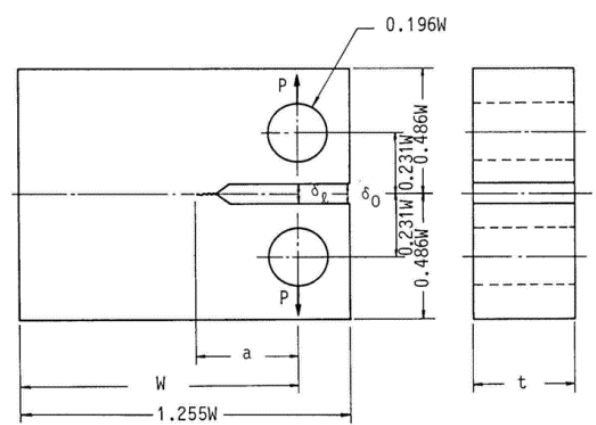

Fig. 6. WOL sample diagram 
The results of crack surface observations are shown in the photographs below.

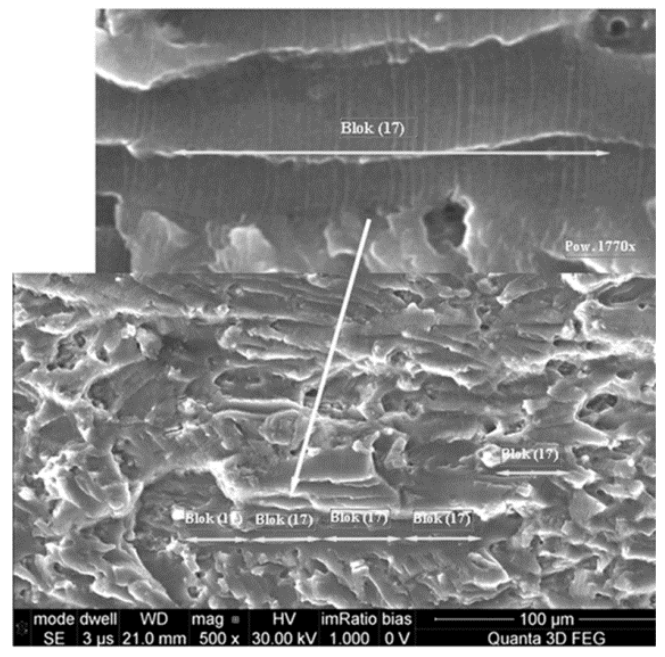

Fig. 7. Image of the microstructure of the sample for the output spectrum from Fig. 2.

Visible blocks of stripes corresponding to 17 cycles with maximum
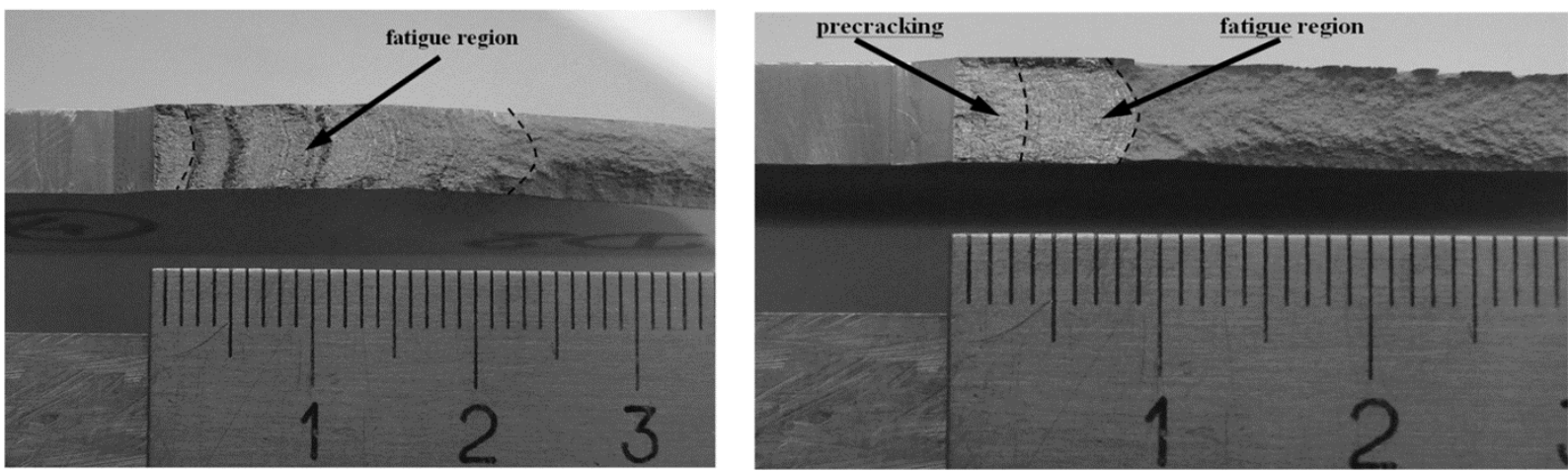

Fig. 8. Examples of crack surfaces after fatigue tests

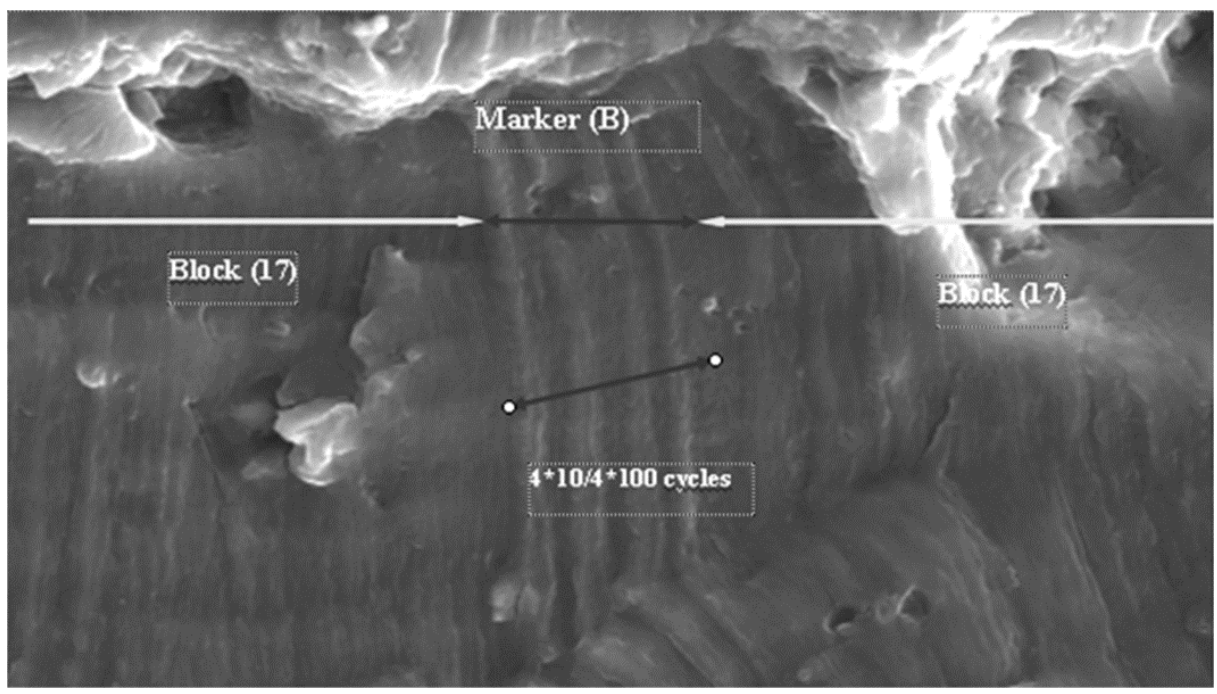

Fig. 9. (B) marker visible on the crack surface. Magnification $x 2250$ 


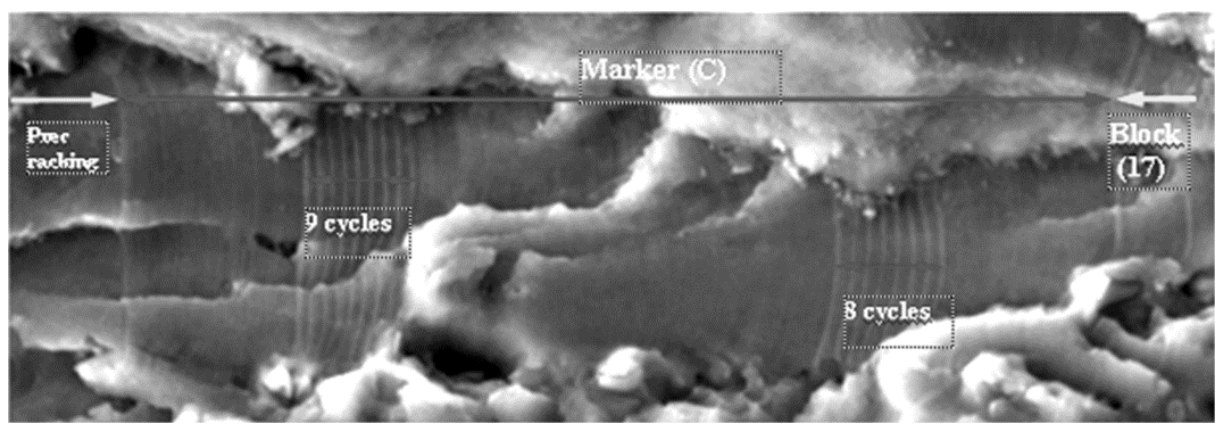

Fig. 10. (C) marker visible on the crack surface. Magnification x1400

After analyzing the pilot fatigue test results the following conclusions were made:

a) Marker modification of the load spectrum brings positive effects in the fatigue structure of cracks.

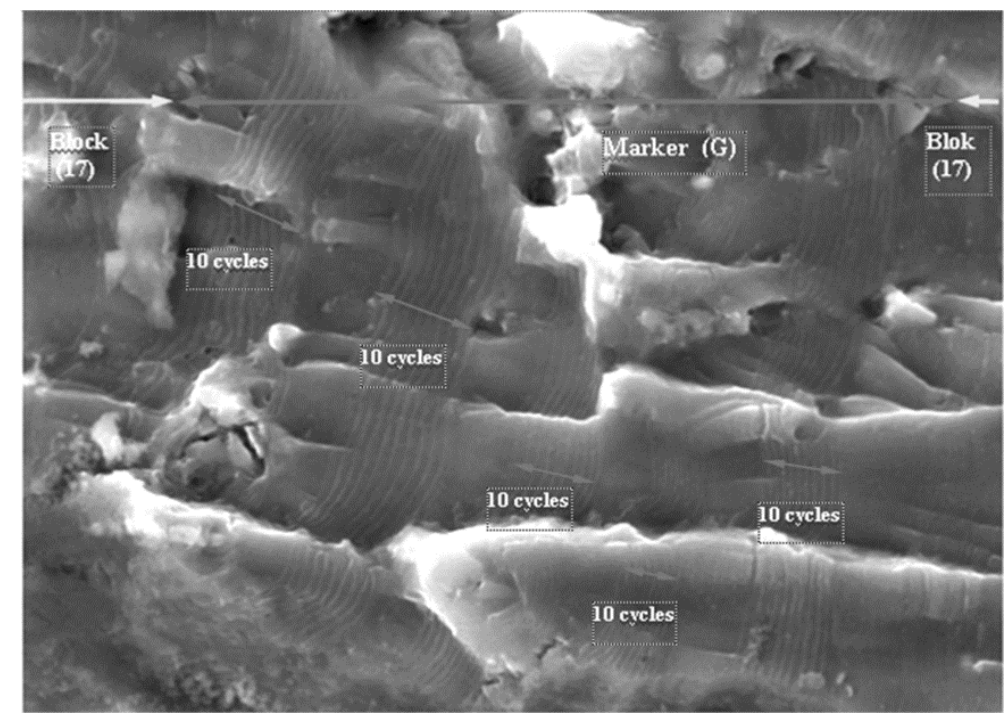

Fig. 11. (G) marker visible on the crack surface. Magnification x2100

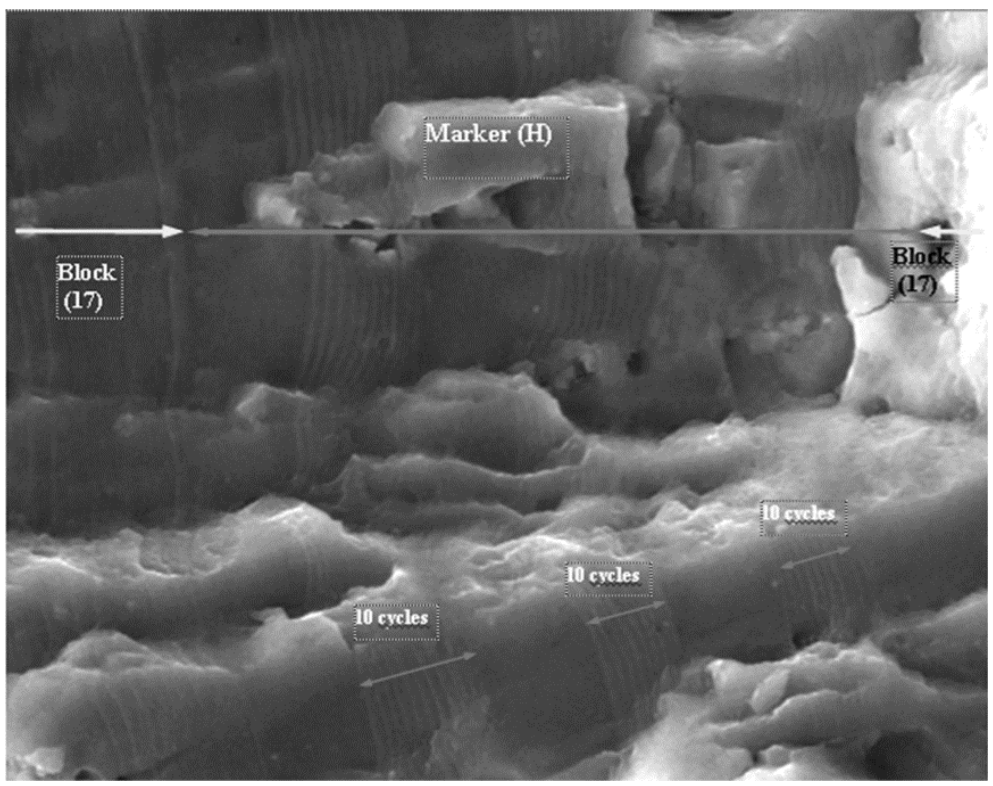

Fig. 12. (H) marker visible on the crack surface Magnification $x 2350$ 


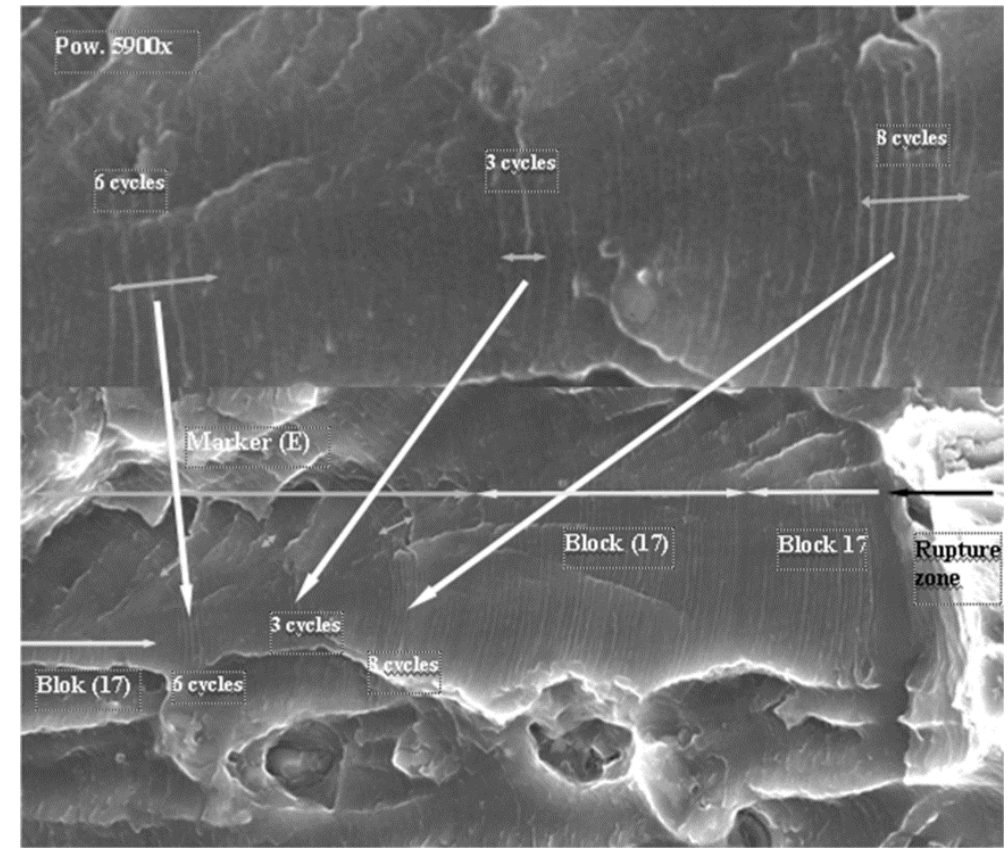

Fig. 13. (E) marker visible on the crack surface. Magnification $x 1800 x$

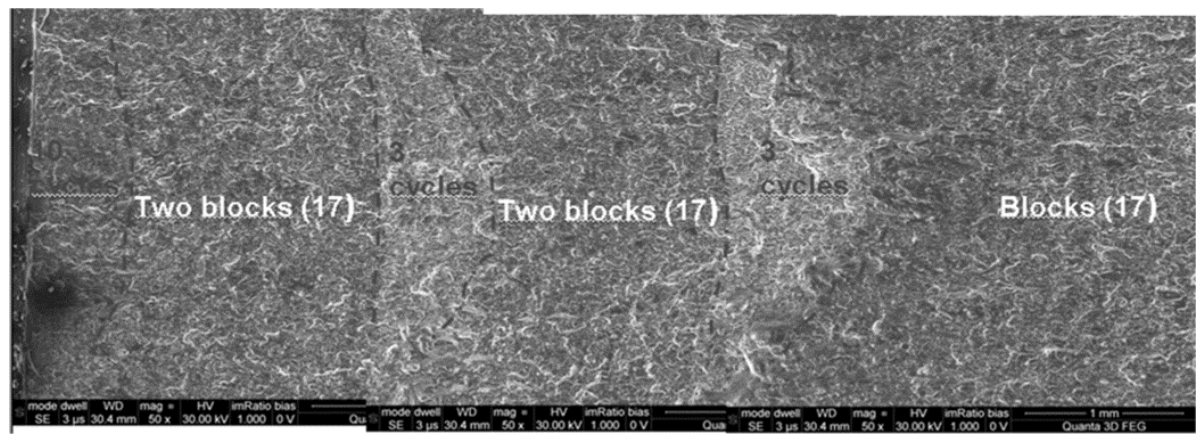

Fig. 14. (e) markers visible on the crack surface

b) The effect of the implemented changes on the Full Scale Fatigue Test spectrum cannot be clearly determined, mainly due to:

- the level of load amplitudes necessary in the long-term testing is lower than the levels of amplitudes used in the present study, which does not guarantee identical results,

- limited scope of testing performed, which does not allow full verification and evaluation:

- the influence of the applied spectrum modifications on the overall fatigue life of tested aircraft elements (change in the load spectrum intensity),

- the reproducibility of the obtained results for structure elements with different geometrical shapes (especially thickness) and with different load forms (bending and torque combined).

\section{CONCLUSIONS}

1) The introduction of markers for FullScale Fatigue Test of PZL-130 Orlik TC-II included:

- Analysis and selection of a method

- Development of load marker variants

- Crack propagation tests carried out in the selected types of aluminum alloy samples. 
2) Selection of natural markers resulting from changing the order of load cycles (Reordering) was proposed.

3) Examples of Full Scale Fatigue Test spectra on the basis of the output spectrum were presented.

4) Since the overall intensity of the applied load spectrum and the consistency with the measured actual flight profile are crucial, the most favorable method of introducing fatigue markers is reordering flights within a load spectrum so that flights exhibiting the highest structural loads are cumulated in one or more groups, preferably of unequal length, in order to differentiate them during inspection, which will allow researchers to distinguish markers on the fatigue crack surface and analyze fatigue behavior of the tested structure and material.

5) The conducted tests clearly show that there are several methods of introducing fatigue markers on the crack surface. However, the final outcome of the Full Scale Fatigue Test is difficult to predict since it depends on the total complex load.

\section{REFERENCES}

[1] Barter S.A., Molent L., Wanhill R.J.H.(2009). Marker loads for quantitative fractography of fatigue cracks in aerospace alloys. Proceedings of the $25^{\text {th }}$ ICAF Symposium of the International Committee on Aeronautical Fatigue, Rotterdam, The Netherlands, May 2009, p. $15-54$

[2] Wanhill R.J.H., Barter S.A. (1994). NLR Technical Publication TP 94177 U, National Aerospace Laboratory NLR, Amsterdam, 1994.

[3] Podskarbi S. (2010). Dokumentacja techniczna z zabudowy czujników tensometrycznych na płatowcu PZL-130 Orlik TC-II nr boczny 037. Warszawa: ITWL. (Sprawozdanie Nr $89 / 31 / 2010)$

[4] Leski A. (2010). Wyznaczenie sekwencji obciążen do próby zmęczeniowej samolotu PZL-130 Orlik TC-II Etap I - wyznaczenie reprezentatywnej sekwencji złożonej z zarejestrowanych lotów badawczych. Warszawa: ITWL. (Sprawozdanie Nr 152/31/2010)

[5] Zgrzywa F. (2010). Sprawozdanie z wykonania lotów próbnych doświadczalnych do pomiaru obciązeń konstrukcji samolotu PZL-130 „Orlik” TC-II systemem KAM-500. Warszawa: ITWL. (Sprawozdanie Nr 4/36/2010)

[6] Fawaz A.S. (2000). Equivalent initial flaw size testing and analysis. Ohio USA: Air Force Research Laboratory. (Report Nr AFRL-VA-TR-2000-3024)

[7] Anderson I. A., Parker G. R.: Full scale fatigue test of the Pilatus PC9/A trainer aircraft, DSTO-TN-0206 PR, Aeronautical and Maritime Research Laboratory, Defense Science and Technology Organization, Australia

[8] Colin M. (1999). A Review of Australian and New Zealand Investigations on Aeronautical Fatigue During the Period April 1997 to March 1999, DSTO Report, Australia, 1999

[9] Lisiecki J. i zespół (2011). Wprowadzenie markerów do sekwencji obciażeń próby zmęczeniowej PZL-130 Orlik TC-II. Warszawa: ITWL. (Sprawozdanie Nr 51/31/2011) 